\title{
Intercultural Communicative Competence Teaching and Assessment Based on Modern Information Technology
}

\author{
https://doi.org/10.3991/ijet.v16i07.21369 \\ Bingzhuan Peng \\ Harbin University of Science and Technology, Harbin, China \\ pengbingzhuan@163. com
}

\begin{abstract}
The integrated and internationalized global economy, international exchanges, and cultural integration increased the frequency of intercultural communication, calling for intercultural communication talents. Thus, the cultivation of students' intercultural communication skills garnered widespread attention. To better and fairly assess college students' actual Intercultural communicative competence (ICC) and effectively cultivate students' ICC, first, this study comprehensively explored the internal relationship between linguistic subjectivity and intercultural communication. Second, an ICC teaching model from the perspective of linguistic subjectivity based on modern information technology (MIT) was constructed, and a college student ICC assessment scale covering 7 dimensions and 36 variables was designed. Finally, an empirical teaching experiment was conducted to verify the credibility and validity of the constructed teaching model and assessment scale. Results show that the 7 dimensions and 36 variables of the constructed assessment scale can effectively measure students' ICC. Students' ICC can be enhanced by exploring the college student ICC teaching model from the perspective of linguistic subjectivity based on MIT, and the backwash effect of ICC teaching and assessment can effectively boost college students' intercultural communicative sensitivity, comprehensive cultural literacy, and practical language application skills.
\end{abstract}

Keywords - Intercultural communicative competence (ICC); linguistic subjectivity; assessment; modern information technology (MIT)

\section{Introduction}

In 2009, United Nations Educational, Scientific and Cultural Organization (UNESCO) released "Investing in Cultural Diversity and Intercultural Dialogue", emphasized that understanding different cultures is a new type of cultural literacy, and considered as important as letters and digital literacy [1]. In 2013, UNESCO released "Intercultural Competence: Basic Concepts and Practice Framework," which clarifies the importance, concept, training purpose, and training practice plan of intercultural competence [2]. The 2015 University English Teaching Guide clearly states that the main contents of college English teaching are general English, English for specific purposes, and intercultural communication. Thus, intercultural communication was 
formally included among the basic contents of college English teaching. Accordingly, the college English teaching of college students' intercultural communicative competence (ICC) should receive considerable attention. Teaching and assessment are integrated, inseparable, and can promote each other. Teaching without assessment cannot be called teaching, and assessment without teaching is meaningless. The results of ICC assessment can promote and serve as a direction for ICC teaching. However, no universally recognized and widely used assessment scale for Chinese college students' ICC exists.

Advanced modern information technology (MIT) provides abundant resources and references for the cultivation and assessment of ICC. In this study, subjectivity is defined as a speaker's beliefs, feelings, attitudes, and stance toward the objective world. However, few existing studies in China are based on MIT, not to mention from the perspective of linguistic subjectivity and based on MIT. Therefore, constructing an assessment scale for Chinese college students' ICC from the perspective of linguistic subjectivity to effectively, fairly, and to comprehensively assess Chinese college students' ICC is important.

\section{State of Art}

Scholars conducted considerable work on ICC, including its definition, elements, and assessment, and teaching models. However, studies on ICC assessment and empirical examination are less discussed. Wang (1990) conducted an ICC assessment for English majors and designed and employed a set of 60-question sociocultural test papers to assess the participants' status in ordinary culture [3]. Sang and Luan (1993) used 58 questions to analyze the intercultural communication pragmatics of English majors [4]. Wang (2006) took 193 non-English majors from two ordinary universities as study objects, collected quantitative study data through questionnaires, and compared and analyzed their ICC [5]. Fan et al. (2013) constructed an ICC selfassessment table and combined it with survey methods such as questionnaires and interviews to conduct an empirical analysis of college students' ICC self-assessment [6]. Moreover, Gao (2014) employed the unity of knowledge and action methodology to construct a theoretical framework for ICC assessment [7]. Peng (2018) proposed a method to examine students' intercultural sensitivity and ICC [8].

Zhao (2015) reviewed empirical study results based on the Affective-BehavioralCognitive (ABC) model and pointed out that clarifying the relationship between three elements, namely, emotions, behaviors, and cognition, is the main direction of future research. Zhao also posited that the main problem in ICC assessment lies in the rash borrowing of the assessment tools of previous scholars or use of only one tool or method [9]. Chen (2016) explored the construction of the ICC Scale for College Students and concluded that the scale can be divided into three dimensions, namely, emotions, cognition, and behaviors, and four difficulty levels, from low to high [10]. Meanwhile, Gan et al. (2018) attempted to build a set of multimodal ICC assessment systems, employing multimodality, such as letter modality, image modality, auditory 
modality, and body modality, and their reasonable combinations to assess college students' ICC at different levels [11].

Byram (1997) proposed that intercultural competence is composed of knowledge, attitudes, skills, and critical cultural awareness. Besides ICC, intercultural competence, language competence, sociolinguistic competence, and discourse competence are also required [12]. Ruben (1979) et al. developed the BASIC scale to measure subjects' behaviors through observation [13]. Tleubay et al. (2020) provides an overview of the aspects to foreign language teaching in the formation of intercultural communicative competence [14]. Koester and Olebe (1988) designed an intercultural communicative behavior assessment scale to assess individual communicative behavior from eight aspects [15]. Furthermore, Kelley and Meyers (1995) constructed an intercultural adaptability scale covering 50 questions to measure individuals' intercultural adaptability in terms of emotional adaptability, flexibility, and openness; perceptual acuity; and individual autonomy [16]. Hammer et al. (2003) created an intercultural development scale with 50 questions to assess individual ICC [17]. Pudikova et al. (2019) suggested several options to develop students' cross-cultural competence [18]. Finally, Sinicrope et al. (2007) summarized a variety of ICC assessment tools, distinguishing between indirect and direct assessment [19].

The above studies mainly discussed ICC from the perspective of specific disciplines, thereby resulting in the lack of universally recognized study results and unified standards. Most studies were restricted to the conceptual integration and theoretical induction of previous studies, lacking new and creative insights. In addition, few empirical studies were conducted, and several empirical studies lacked credibility and were ineffective. Moreover, the focus of most existing assessment methods and ICC assessment scales lacked comprehensiveness. In the current study, in view of the characteristics of the status quo of Chinese college students' ICC, first, the feasibility of ICC from the perspective of linguistic subjectivity is analyzed. Second, on this basis, the dimensions and variables of an ICC assessment scale is designed and a teaching model from the perspective of linguistic subjectivity based on MIT is constructed. Third, taking undergraduates from Harbin University of Science and Technology as the study objects, the study verifies the reliability and effectiveness of the designed dimensions and variables. Finally, the study proves that the dimensions and variables of the ICC assessment scale from the perspective of linguistic subjectivity based on MIT can comprehensively assess college students' ICC and effectively improve Chinese college students' ICC.

The remainder of this study is organized as follows. Section 3 proposes the feasibility of discussing ICC from the perspective of linguistic subjectivity, construct a teaching model, and design an ICC assessment scale from the perspective of linguistic subjectivity based on MIT. Section 4 conducts an empirical investigation using the teaching model and assessment scale to verify their reliability and validity. Section 5 summarizes the entire study and provides related conclusions. 


\section{$3 \quad$ Methodology}

\subsection{Feasibility of exploring ICC from the perspective of linguistic subjectivity}

Language and culture interact, influence each other, and are inseparable. Together, the two concepts realize and fulfil the communicative functions of language. Language cannot be called as such without subjectivity. Language is the carrier of culture. Moreover, language reflects and represents culture. Although language has objective meaning, to achieve the purpose of intercultural communication, language users undoubtedly encode subjectivity in language, that is, their feelings; emotions; attitude toward the objective world based on existing knowledge, experiences, cognition, and the background of the world; and their understanding of the world. Thus, the formation of linguistic subjectivity is inseparable from language users' intercultural communication. Intercultural communication is the process through which language users imprint their thoughts, attitudes, and opinions into their utterances during communication based on their perception and cognition of the objective world. The process through which language users understand and evaluate the objective world is the process through which linguistic subjectivity is formed. Therefore, linguistic subjectivity will inevitably be reflected during the process of intercultural communication. In addition, linguistic subjectivity in intercultural communication has personal, implicit, and nonconventional characteristics. To realize the purpose of intercultural communication, we should pay attention to not only the objective but also the subjective meaning of culture.

\subsection{Construction of the Chinese college student ICC teaching model from the perspective of linguistic subjectivity based on MIT}

Peng (2017) pointed out regulated new teaching patterns should be associated with modem information technology, especially Internet-based devices to make English teaching and learning easily accessible [20]. A Chinese college student ICC teaching model from the perspective of linguistic subjectivity based on MIT is constructed, as shown in Fig. 1. 


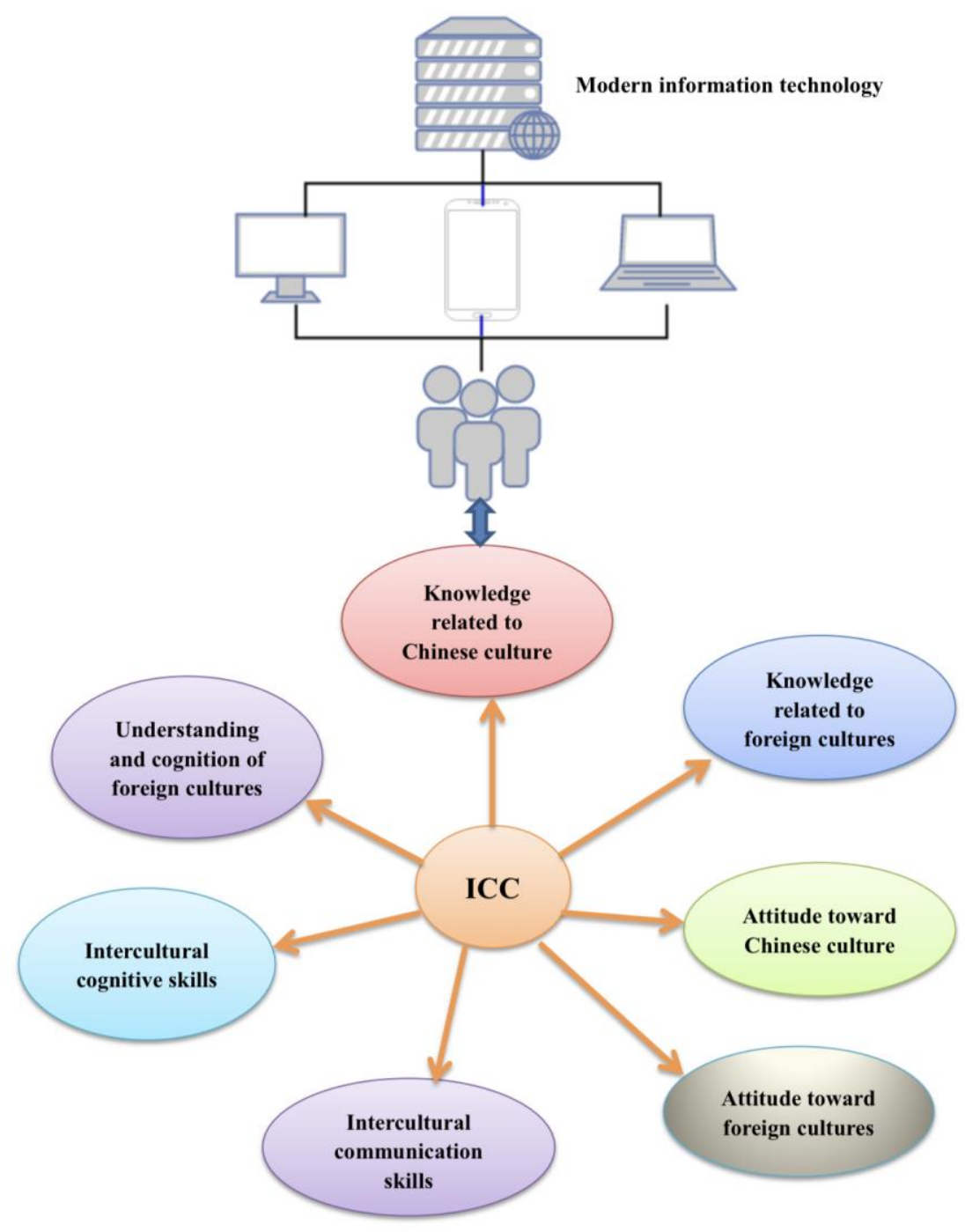

Fig. 1. Chinese College Student ICC Teaching Model from the Perspective of Linguistic Subjectivity Based on MIT

In this model, seven dimensions of students' ICC are covered, that is, knowledge related to Chinese culture, knowledge related to foreign cultures, attitude toward Chinese culture, attitude toward foreign cultures, intercultural communication skills, intercultural cognitive skills, and understanding and cognition of foreign cultures. 
In this model, teachers can use MIT, and students can use desktop computers, laptops, mobile phones, and other means to access information anytime, anywhere. Teachers can also obtain intercultural input, perceive different cultures, and deeply understand intercultural similarities and differences. At the same time, teachers can use MIT to communicate with students in real time, answer questions, and monitor students' learning. Meanwhile, students can use online communication platforms, such as QQ, WeChat, email, and other interactive methods, to imitate intercultural scenes, obtain intercultural output, and simulate intercultural communication with classmates and teachers. Students can also engage in intercultural communication with people from different countries.

\subsection{Design of ICC assessment scale dimensions and variables}

We draw on two ICC models that are highly recognized by international academic circles, that is, ICC model by Byram (1997) as shown in Fig. 2, and Pyramid Model of Intercultural Competence by Deardorff (2009) as shown in Fig. 3 [21]. In addition, the intercultural competence assessment scale (a yoga form) compiled by Fantini $(2000,2006)$ is employed as a reference, which includes four dimensions and 22 descriptive items, and the Federal International Life Experience Research Project Intercultural Competence Evaluation Scale, with four dimensions and 43 descriptive items [22]. Accordingly, the study designs an ICC assessment scale consisting of seven dimensions and 36 variables, which is appropriate for Chinese college students, from the perspective of linguistic subjectivity. The seven dimensions are knowledge related to Chinese culture (D1), knowledge related to foreign cultures (D2), attitude toward Chinese culture (D3), attitude toward foreign cultures (D4), intercultural communication skills (D5), intercultural cognitive skills (D6), and understanding and cognition of foreign cultures (D7). 


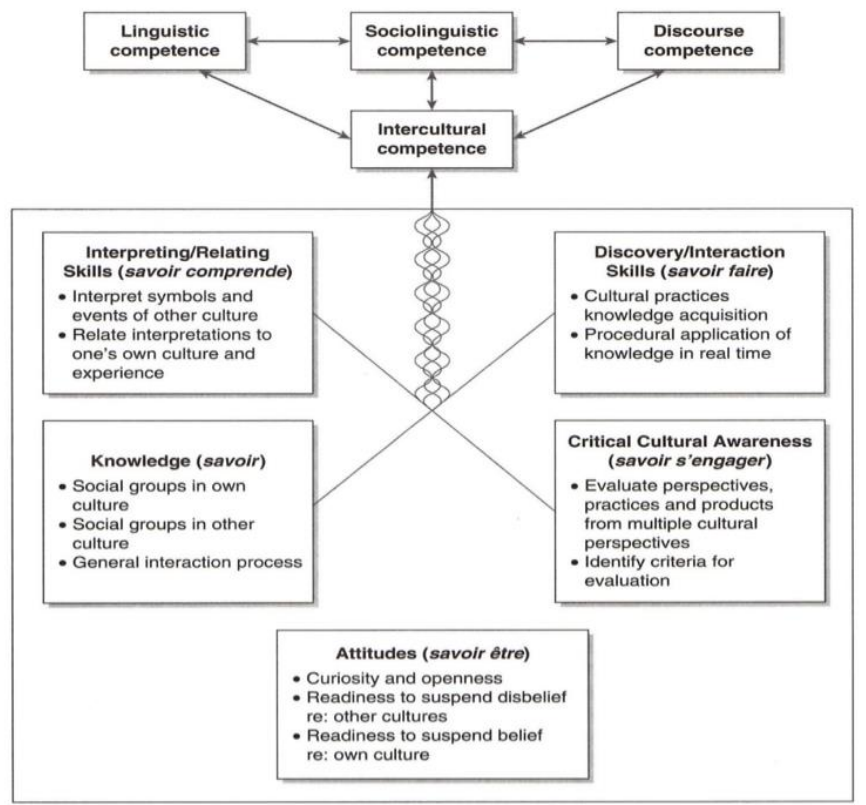

Fig. 2. ICC Model

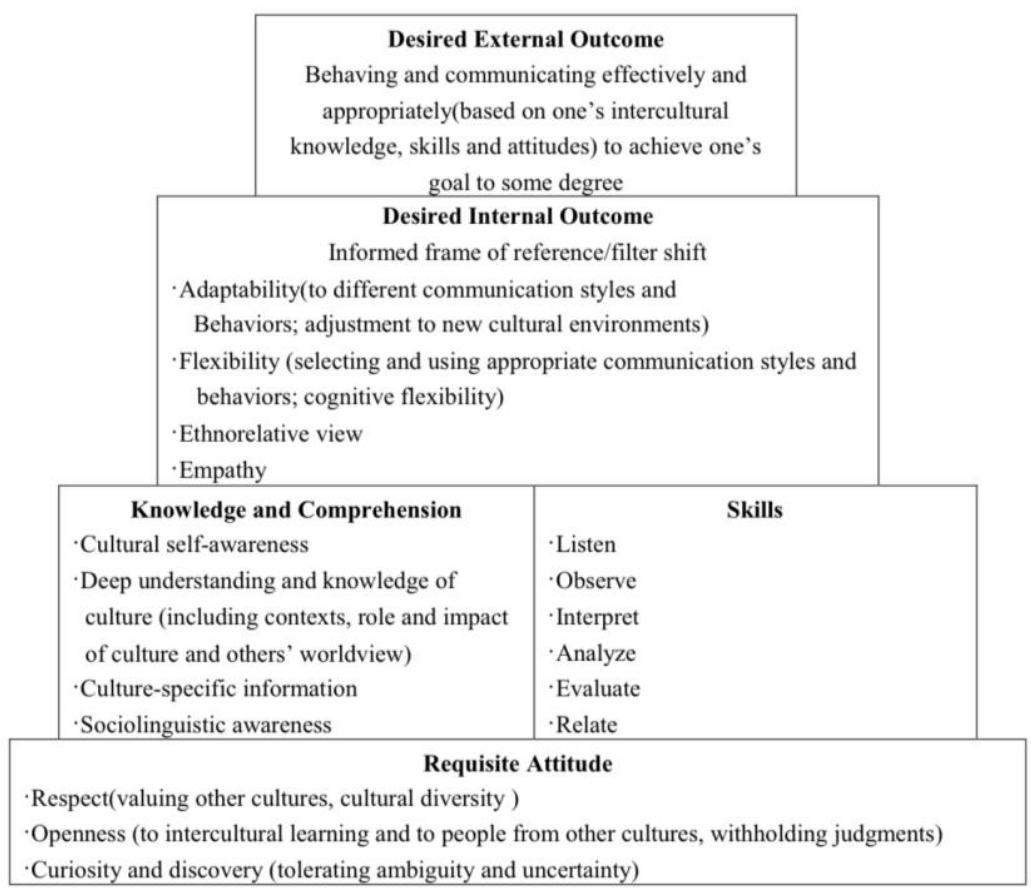

Fig. 3. Pyramid Model of Intercultural Competence 
Knowledge related to Chinese culture: Knowledge related to Chinese culture (D1) refers to the ability to understand Chinese cultural knowledge. Four variables are in D1. Variable 1 is Chinese cultural background, such as society, politics, history, and geography. Variable 2 is Chinese lifestyle, regional customs, habits, and so on. Variable 3 is Chinese social communication etiquette and codes of conduct. Variable 4 is Chinese values, worldviews, religious and cultural beliefs, and so on.

Knowledge related to foreign cultures: Knowledge related to foreign cultures (D2) refers to the ability to understand foreign cultural knowledge. Eight variables are included in D2. Variable 1 is foreign cultural background, such as society, politics, history, and geography. Variable 2 is foreign lifestyles, regional cultural customs, and habits. Variable 3 is foreign social etiquette norms. Variable 5 is foreign conduct codes. Variable 5 is foreign values, worldviews, religious and cultural beliefs, and so on. Variable 6 is foreign cultural taboos. Variable 7 is communication channels and methods. Variable 8 is the ways, methods, techniques, and strategies employed by successful foreigners for intercultural communication.

Attitude toward Chinese culture: Attitude toward Chinese culture (D3) involves perceiving, learning, understanding, and promoting Chinese-thinking culture from multiple perspectives with a positive attitude. D3 has five variables. Variable 1 is actively communicating and learning with Chinese people. Variable 2 is accepting, tolerating, and understanding the different values, worldviews, beliefs, eating habits, ways of doing things, codes of conduct, and taboos of different regions. Variable 3 is accepting one's own culture, customs, cultural identity and respecting the cultures as well as cultural identity of others. Variable 4 is having an interest in and curiosity about Chinese culture. Variable 5 is being willing to deeply understand Chinese cultural backgrounds, contexts, knowledge, and influences.

Attitude toward foreign cultures: Attitude toward foreign cultures (D4) refers to positive attitudes toward foreign cultures from different perspectives. Six variables are in D4. Variable 1 is willingness to communicate and learn from foreigners from different cultures. Variable 2 is the ability to understand and accept foreigners' ideas, values, worldviews, beliefs, eating habits, ways of doing things, codes of conduct, taboos, and so on. Variable 3 is willingness to learn foreign languages and understand foreigners. Variable 4 is willingness to accept foreign cultures and respect their cultural identities. Variable 5 is the interest in and curiosity about foreign cultures. Variable 6 is the ability to understand foreign cultural backgrounds, contexts, knowledge, and influences.

Intercultural communication skills: Intercultural communication skills (D5) refer to the ability to correctly recognize, tolerate, and accept cultural phenomena, customs, and habits that differ from or contradict the national culture. D5 includes seven variables. Variable 1 is the ability to communicate with others and explain Chinese culture when communication misunderstandings arise. Variable 2 is the ability to express meaning through body language when meaning cannot be accurately expressed by language. Variable 3 is the ability to communicate with people with different cultural backgrounds. Variable 4 is the ability to treat foreigners with respect and courtesy, fairness, and justice to achieve successful communication. Variable 5 is the ability to sensitively identify differences among different cultures. Variable 6 is the ability to 
view and analyze events in foreign countries from different cultural perspectives. Variable 7 is the ability to avoid private topics as much as possible.

Intercultural cognitive skills: Intercultural cognitive skills (D6) refer to the ability to communicate with foreigners from different cultures by learning and acquiring their communication methods, skills, and strategies. Three specific variables are included. Variable 1 is the ability to directly acquire knowledge about intercultural communication through contact with foreigners. Variable 2 is the ability to learn foreign languages and cultures using various methods, skills, and strategies. Variable 3 is the ability to reflect, learn, and find proper solutions to intercultural conflicts and misunderstandings.

Understanding and cognition of foreign cultures: Understanding and cognition of foreign cultures (D7) refer to people's understanding and cognition of the differences among different cultures. D7 involves three variables. Variable 1 is the understanding and realizing the differences and similarities among different cultures. Variable 2 is having an awareness of one's cultural identity when communicating with foreigners with different cultural identities. Variable 3 is having an awareness of differences between one's and others' cultural style and language use.

\section{Teaching Example and Assessment Results}

\subsection{Study objects}

The study objects were college freshmen from Harbin University of Science and Technology. The control group consisted of three classes of electrical majors, mechanical majors, and measurement and communication majors, with 117 students. To ensure the reliability of the experiment, students with the same three majors were chosen for the experimental group, consisting of 119 students with scores and numbers similar to those of the students in the control group. The Chinese college student ICC teaching model from the perspective of linguistic subjectivity based on MIT was employed in the control and experimental groups for an entire semester (i.e., four months).

\subsection{Study instrument}

We mainly used questionnaires, that is, the Chinese college student ICC assessment scale, and interviews to assess the college students' ICC. The questionnaire included seven dimensions and 36 variables of college students' ICC, with 36 fivepoint scales. Moreover, the questionnaire consisted of 36 questions, for a total score of 180 points. After an entire-semester ICC teaching experiment, the study employed MIT to obtain the $M$ value, SD value and $\mathrm{P}$ value using the following formulas for the data of the experimental group and the control group. And also, the data were analyzed. 


$$
M=\frac{X_{1}+X_{1}+\ldots \ldots+X_{n}}{N}
$$

In formula (1), $M$ stands for the mean (i.e., average value) of the samples, such as $X_{1}, X_{2}, \ldots, X_{n}$.

$$
\begin{gathered}
M A X=\max \left(X_{i}\right) i \in[1, N] \\
M I N=\min \left(X_{i}\right) i \in[1, N] \\
S D=\sqrt{\frac{1}{N-1} \sum_{i=1}^{N}\left(X_{i}+\bar{X}\right)^{2}}
\end{gathered}
$$

SD (Standard deviation) in formula (4) can reflect the dispersion degree of the data set. The smaller the SD is, the smaller the deviation from the M will be, and vice versa. The size of the SD can be measured by the multiplier relationship between the $\mathrm{SD}$ and M. For two data sets with the same M, the SD may not be the same. $\bar{x}$ is the average value of the samples in the experiment.

$$
P=\left\{\begin{array}{l}
2\left[1-\Phi\left(z_{0}\right)\right] \text { When the tested hypothesis } \mathrm{H}_{1} \text { is } \mathrm{P} \text { and } \mathrm{P} \text { is not equal to } 0 . \\
1-\Phi\left(z_{0}\right) \text { When the tested hypothesis } \mathrm{H}_{1} \text { is } \mathrm{P} \text { and } \mathrm{P} \text { is more than to } 0 . \\
\Phi\left(z_{0}\right) \text { When the tested hypothesis } \mathrm{H}_{1} \text { is } \mathrm{P} \text { and } \mathrm{P} \text { is less than to } 0 .
\end{array}\right.
$$

In formula (5), $\mathrm{P}$ value is the probability of a sample observation result or more extreme result when the null hypothesis is true. If $\mathrm{P}$ value is small, it means that the occurrence probability of the null hypothesis is also small, and if it does, we have reasons to reject the null hypothesis. Meanwhile, the smaller the $\mathrm{P}$ value is, the more significant the result will be.

In addition, interviews were conducted during and after the experiment to determine the college students' satisfaction degree with intercultural communication teaching contents and methods in college English courses.

\subsection{Assessment results}

Table 1 presents a comparison of the ICC total scores of the students in the experimental and control groups for the pretest and posttest. A total of 117 and 119 questionnaires were distributed in the control and experimental groups, respectively, and 117 and 119 valid questionnaires were retrieved. The valid questionnaires accounted for $100 \%$ of the total questionnaires distributed. Table 1 shows that before the experiment, the control group's highest ICC score was 125 points and lowest score was 40 points, with an average score of 87.52 points. After the experiment, the control group's highest ICC score was 130 points and lowest score was 40 points, with an average score of 88.45 points. Meanwhile, before the experiment, the experimental group's highest ICC score was 120 points and lowest score was 45 points, with an 
average score of 87.69 points. Finally, after the experiment, the experimental group's highest ICC score was 170 points and lowest score was 75 points, with an average score of 110.68 points.

Table 1. Comparison of ICC total scores between students in experimental and control groups

\begin{tabular}{|c|c|c|c|c|c|c|c|c|c|c|c|c|c|}
\hline \multirow{2}{*}{$\mathrm{ICC}$} & \multirow[b]{2}{*}{$N V Q R$} & \multirow[b]{2}{*}{$N$} & \multicolumn{4}{|c|}{ Control Group } & \multicolumn{6}{|c|}{ Experimental Group } & \multirow{2}{*}{$\mathbf{P}$} \\
\hline & & & $\operatorname{Max}$ & Min & $M$ & $S D$ & $N V Q R$ & $N$ & $\operatorname{Max}$ & $\operatorname{Min}$ & $M$ & $S D$ & \\
\hline Pretest & 117 & 117 & 125 & 40 & 87.52 & 2.5 & 119 & 119 & 120 & 45 & 87.69 & 2.3 & 0.079 \\
\hline Posttest & 117 & 117 & 130 & 40 & 88.45 & 2.7 & 119 & 119 & 170 & 75 & 110.68 & 2.2 & 0.002 \\
\hline
\end{tabular}

NVQR: Number of valid questionnaires returned Total score: 180

Before the experiment, the $\mathrm{P}$ value of the control and experimental groups was $0.079(>0.05)$, indicating the absence of a significant difference between the two groups. However, after the experiment, the $\mathrm{P}$ value of the control and experimental groups was $0.002(<0.05)$, showing the significant difference between the two groups. Furthermore, after the experiment, the experimental group's average ICC score was 22.23 points higher than that of the control group. This result indicated that the ICC of the experimental group was significantly higher than that of the control group. Therefore, the constructed assessment scale can effectively measure the college students' ICC and contribute to ICC improvement.

Table 2. Comparison of seven dimensions of ICC between control and experimental groups

\begin{tabular}{|c|c|c|c|c|c|c|c|c|}
\hline \multirow[b]{2}{*}{$\begin{array}{c}\text { Seven } \\
\text { Dimensions }\end{array}$} & \multirow[b]{2}{*}{$\begin{array}{l}\text { Total } \\
\text { score }\end{array}$} & \multicolumn{3}{|c|}{ Control group } & \multicolumn{3}{|c|}{ Experimental group } & \multirow[b]{2}{*}{$\mathbf{P}$} \\
\hline & & $M$ & $S D$ & $\begin{array}{c}\text { Std. error } \\
\text { mean }\end{array}$ & $M$ & $S D$ & $\begin{array}{l}\text { Std. error } \\
\text { mean }\end{array}$ & \\
\hline D1 & 20 & 14.26 & 2.715 & .48954 & 17.85 & 2.034 & .42187 & 0.000 \\
\hline D2 & 40 & 30.24 & 3.748 & .47126 & 36.17 & 2.716 & .31523 & 0.003 \\
\hline D3 & 25 & 18.83 & 2.616 & .48578 & 22.41 & 2.005 & .32256 & 0.019 \\
\hline D4 & 30 & 22.15 & 3.147 & .51245 & 27.24 & 2.745 & .47802 & 0.007 \\
\hline D5 & 35 & 25.32 & 3.912 & .64182 & 31.36 & 3.018 & .31457 & 0.001 \\
\hline D6 & 15 & 10.67 & 2.415 & .59098 & 13.52 & 2.012 & .54125 & 0.000 \\
\hline D7 & 15 & 11.91 & 2.353 & .41526 & 13.88 & 2.014 & .31784 & 0.002 \\
\hline
\end{tabular}

D1=knowledge related to Chinese culture

D2=knowledge related to foreign cultures

D3=attitude toward Chinese culture

D4=attitude toward foreign cultures

D5=intercultural communication skills

D6=intercultural cognitive skills

D7=understanding and cognition of foreign cultures

Table 2 shows a comparison of the seven dimensions of ICC between the control and experimental groups at the end of the semester. The college students' ICC was 
classified into seven dimensions. The total score of D1 is 20 points, that of D2 is 40 points, that of D3 is 25 points, that of D4 is 30 points, that of D5 is 35 points, that of D6 is 15 points; and that of D7 is 15 points.

In Table 2, the average score of the students in the experimental group in knowledge related to Chinese culture was 3.59 points higher than that of the control group, with a $\mathrm{P}$ value of 0.000 . The experimental group's average score in knowledge related to foreign cultures was 5.93 points higher than that of the control group, with a $\mathrm{P}$ value of 0.003 . Moreover, the experimental group's average score in attitude toward Chinese culture was 3.58 points higher than that of the control group, with a $\mathrm{P}$ value of 0.019. The experimental group's average score in attitude toward foreign cultures was 5.09 higher than that of the control group, and the $\mathrm{P}$ value was 0.007 . The experimental group's average score in intercultural communication skills was 6.04 points higher than that of the control group, with a $\mathrm{P}$ value of 0.001 . The average score of the students in the experimental group in understanding and cognition of foreign cultures was 2.85 points higher than that of the students in the control group, with a $\mathrm{P}$ value of 0.000 . Finally, the experimental group's average score in understanding and cognition of foreign cultures was 1.97 points higher than that of the control group, with a $\mathrm{P}$ value of 0.002 . These findings showed that the experimental group's average score for each dimension of intercultural communication skills was also significantly higher than that of the control group. In addition, the $\mathrm{P}$ value of the average score comparison was less than 0.05 , thereby indicating that a significant difference existed between the control group's ICC and the experimental group's ICC.

Table 3. Contrast between seven dimensions of ICC of control group in pretest and posttest

\begin{tabular}{|c|c|c|c|c|c|c|c|c|c|}
\hline \multirow{2}{*}{$\begin{array}{c}\text { Seven dimensions of ICC } \\
\text { of control group }\end{array}$} & \multicolumn{4}{|c|}{ Pretest } & \multicolumn{4}{c|}{ Posttest } & \multirow{2}{*}{ P } \\
\cline { 2 - 11 } & Max & Min & $\boldsymbol{M}$ & $\boldsymbol{S D}$ & $\boldsymbol{M a x}$ & $\boldsymbol{M i n}$ & $\boldsymbol{M}$ & $\boldsymbol{S D}$ & \\
\hline D1 & 15 & 5 & 12.07 & 1.452 & 20 & 5 & 13.01 & 1.192 & 0.061 \\
\hline D2 & 35 & 5 & 29.52 & 1.389 & 40 & 5 & 29.86 & 1.424 & 0.075 \\
\hline D3 & 20 & 5 & 17.69 & 1.264 & 25 & 10 & 18.72 & 1.135 & 0.089 \\
\hline D4 & 15 & 10 & 20.99 & 1.282 & 30 & 5 & 20.68 & 1.504 & 0.073 \\
\hline D5 & 20 & 5 & 25.67 & 1.016 & 35 & 10 & 26.35 & 1.257 & 0.068 \\
\hline D6 & 10 & 0 & 11.04 & 1.141 & 15 & 5 & 11.89 & 1.228 & 0.085 \\
\hline D7 & 10 & 5 & 10.86 & 1.026 & 15 & 5 & 10.77 & 1.014 & 0.067 \\
\hline
\end{tabular}

Table 4. Contrast between seven dimensions of ICC of experimental group in pretest and posttest

\begin{tabular}{|c|c|c|c|c|c|c|c|c|c|}
\hline \multirow{2}{*}{$\begin{array}{c}\text { Seven dimensions of ICC of } \\
\text { experimental group }\end{array}$} & \multicolumn{4}{|c|}{ Pretest } & \multicolumn{4}{c|}{ Posttest } & \multirow{2}{*}{ P } \\
\cline { 2 - 11 } & $\boldsymbol{M a x}$ & $\boldsymbol{M i n}$ & $\boldsymbol{M}$ & $\boldsymbol{S D}$ & $\boldsymbol{M a x}$ & $\boldsymbol{M i n}$ & $\boldsymbol{M}$ & $\boldsymbol{S D}$ & \\
\hline D1 & 15 & 5 & 11.48 & 1.547 & 20 & 10 & 15.47 & 1.231 & 0.025 \\
\hline D2 & 30 & 5 & 30.14 & 1.258 & 40 & 15 & 36.56 & 1.065 & 0.000 \\
\hline D3 & 15 & 5 & 18.65 & 1.369 & 25 & 15 & 22.41 & 1.547 & 0.014 \\
\hline D4 & 20 & 10 & 21.47 & 1.244 & 25 & 20 & 26.77 & 1.245 & 0.008 \\
\hline D5 & 20 & 10 & 25.93 & 1.625 & 35 & 30 & 31.25 & 1.054 & 0.000 \\
\hline D6 & 10 & 5 & 10.24 & 1.206 & 15 & 10 & 13.34 & 1.149 & 0.021 \\
\hline D7 & 5 & 0 & 10.96 & 1.314 & 15 & 10 & 13.69 & 1.282 & 0.012 \\
\hline
\end{tabular}


Table 3 demonstrates the contrast between the seven dimensions of ICC of the control group in the pretest and posttest. After the experiment, the average scores of the seven dimensions of the students' ICC differed slightly from those before the experiment, and all the $\mathrm{P}$ values were more than 0.05 , indicating that no significant difference existed in the control group's ICC. Table 4 exhibits the contrast between the seven dimensions of ICC of the experimental group in the pretest and posttest. After the experiment, the average scores of the seven dimensions of the students' ICC were 3.99 points, 6.42 points, 3.76 points, 5.3 points, 5.32 points, 3.1 points and 2.73 higher than those before the experiment. The $\mathrm{P}$ values of each average score before and after the experiment were all less than 0.05 , reflecting the significant difference in ICC between the control and experimental groups.

Table 5. Satisfaction degree with intercultural communication teaching in college English of control and experimental groups in posttest

\begin{tabular}{|l|c|c|c|c|c|c|c|c|c|c|c|}
\hline & & \multicolumn{2}{|c|}{ Very satisfied } & \multicolumn{2}{c|}{ Quite satisfied } & \multicolumn{2}{c|}{$\begin{array}{c}\text { Generally } \\
\text { satisfied }\end{array}$} & \multicolumn{2}{c|}{$\begin{array}{c}\text { Not very } \\
\text { satisfied }\end{array}$} & \multicolumn{2}{c|}{ Not satisfied } \\
\cline { 2 - 14 } & $\begin{array}{c}\text { Total } \\
\boldsymbol{N}\end{array}$ & $\boldsymbol{N}$ & $\boldsymbol{P}(\boldsymbol{\%})$ & $\boldsymbol{N}$ & $\boldsymbol{P}(\boldsymbol{\%})$ & $\boldsymbol{N}$ & $\boldsymbol{P}(\%)$ & $\boldsymbol{N}$ & $\boldsymbol{P}(\%)$ & $\boldsymbol{N}$ & $\boldsymbol{P}(\%)$ \\
\hline Control group & 117 & 16 & 13.68 & 39 & 33.33 & 45 & 38.46 & 10 & 8.55 & 7 & 5.98 \\
\hline $\begin{array}{l}\text { Experimental } \\
\text { group }\end{array}$ & 119 & 40 & 33.61 & 61 & 51.26 & 13 & 10.93 & 3 & 2.52 & 2 & 1.68 \\
\hline
\end{tabular}

$\mathrm{N}=$ number

$\mathrm{P}=$ percentage

Table 5 presents the control and experimental groups' degree of satisfaction with intercultural communication teaching in college English in the posttest. In the experimental group, 101 students were very satisfied and quite satisfied with college English intercultural communication teaching, accounting for $84.87 \%$ of the total number of students, which was considerably higher than the percentage of students in the control group. Meanwhile, in the experimental group, the total number of students who were generally satisfied, not very satisfied, and not satisfied with college English intercultural communication teaching was only 18 , accounting for $15.13 \%$ of the total number of students, which was significantly lower than the percentage of students in the control group. These findings showed that the investigation of the ICC teaching model and assessment scale from the perspective of linguistic subjectivity based on MIT effectively improved the students' satisfaction with college English intercultural communicative teaching.

\section{Conclusion}

The concept of promoting learning and teaching with assessment was adhered to and a college student ICC teaching model and assessment scale from the perspective of linguistic subjectivity based on MIT was constructed. In addition, the credibility and validity of the assessment scale were verified. The study aimed to enhance students' ICC, cultivate qualified intercultural communicative talents, and promote inter- 
cultural communicative teaching. Based on the results, the following conclusions could be drawn:

First, this study can increase students' interest in intercultural learning and intercultural input, promote students' intercultural output, enable students to engage in successful intercultural communication, promote the personalized development of students' intercultural communication skills, and improve students' practical language application skills.

Second, this study can enable Chinese college students to properly and effectively understand foreign cultures, gain a deep understanding of their own cultures as well as foreign cultures, and cultivate open and tolerant concepts and attitudes and encourage students to directly, quickly, and frequently interact with foreign cultures.

Third, this study can help Chinese college students measure and predict their actual level of ICC, form and enhance their intercultural communication awareness, and improve their intercultural communication sensitivity.

Fourth, this empirical study can improve intercultural communicative teaching and the college student ICC assessment scale, enrich the literature on ICC assessment, and provide ideas and methods for similar studies.

Fifth, the results of the assessment can provide guidance for improving college student ICC teaching; enhancing college English intercultural teaching methods, strategies, and assessment scales; improving the effectiveness of intercultural teaching; and effectively promoting ICC assessment and the cultivation of college students' intercultural communication skills.

Finally, this study can not only comprehensively and systematically measure college students' ICC, promote the reform of college English intercultural teaching, and provide references for domestic colleges and universities to cultivate international talents and relevant cultural competence training courses but also enrich the literature on intercultural communication. The assessment data in this study can also provide guidance for intercultural teaching and a reference for employers. However, this study has several limitations. For example, the study designed seven dimensions and 36 evaluation variables for the college student ICC assessment scale to determine local students' ICC situation but did not consider the students' accumulation of intercultural communication skills in the general learning process. This topic will be the focus of a subsequent study.

\section{Acknowledgement}

This work was supported in part by Heilongjiang Provincial Educational Science "14th Five-Year Plan" Key Project (GJB1421071); Shanghai International Studies University Foreign Language Teaching Materials Research Institute Foreign Language Textbook Research Project (2020HL0001-YBK); the Tenth China Foreign Language Education Fund Project (ZGWYJYJJ10Z006); Shanghai Foreign Language Education Press National College Foreign Language Teaching and Research Project (2019HL0001B). 


\section{$7 \quad$ References}

[1] J. You, "Analysis of UNESCO's concept and framework of intercultural competence," World Education Information, vol. 11, no. 6, June, pp. 44-49, 2016.

[2] J. Jiao, "A Review of foreign intercultural communication competence in 50 Years," Jinyang Academic Journal, vol.5, no.9, Sep., pp. 117-125, 2017.

[3] Z.Y. Wang, "Analysis of social culture test," Foreign Language Teaching and Research, vol. 4, no. 8, Aug., pp. 32-36, 1990.

[4] S. M. Sang, and S. M. Luan, "Analysis of intercultural communication pragmatic test," Foreign Language and Foreign Language Teaching, vol. 4, no. 8, Aug., pp. 30-34, 1993.

[5] Y. P. Wang, "A comparative study on the intercultural communicative competence of nonEnglish-major EFL learners in different contexts," M. S. thesis, Guangdong University of Foreign Studies, Guangdong, Guangzhou, 2006.

[6] W. Fan, W. P. Wu, and R. Z. Peng, "Analysis of Chinese university students' intercultural competence self-evaluation," Chinese Foreign Languages, vol. 10, no. 11, Nov., pp. 53-59, 2013.

[7] Y. C. Gao, "The theoretical framework of the evaluation system of intercultural communication competence of Chinese university students," Foreign Language World, vol. 4, no. 8, Aug., pp. 80-88, 2014.

[8] B. Z. Peng, "Study on cultivation of intercultural communication competence of college English based on modern information technology," International Journal of Emerging Technologies in Learning, vol. 13, no. 9, Sep., pp. 29-40, 2018. https://doi.org/ 10.3991/ijet.v13i09.8724

[9] X. Zhao, "Research on cross-cultural communication ability evaluation based on ABC model," Journal of Liaoning Medical College (Social Science Edition), vol. 13, no. 5, May, pp. 129-132, 2015.

[10] C. A. Chen, "Study on the scale of intercultural communicative competence for Chinese college students," M. S. thesis, Hunan Normal University, Hunan, Changsha, 2016.

[11] X. Y. Gan, Y. X. Huang, and S. S. Cheng, "Multimodal intercultural communication capability assessment model," Journal of Shenyang University of Technology (Social Science Edition), vol. 11, no. 2, Feb., pp. 92-96, 2018.

[12] M. Byram, Teaching and Assessing Intercultural Communicative Competence. NY: Multilingual Matters, 1997.

[13] B. D. Ruben, and D. J. Kealey, "Behavioral assessment of communication competency and the prediction of cross-cultural adaptation," International Journal of Intercultural Relations, vol. 3, no. 1, Jan., pp. 15-47, 1979. https://doi.org/10.1016/0147-1767(79)90045-2

[14] S. Tleubay, G. Nurzhanova, and S. Ybyshova, "The formation of intercultural communicative competence of future teachers in a trilingual educational environment," International Journal of Emerging Technologies in Learning, vol. 15, no. 17, Sep., pp. 148-164, 2020. https://doi.org/10.3991/ijet.v15i17.14249

[15] J. Koester, and M. Olebe, "The behavioral assessment scale for intercultural communication effectiveness," International Journal of Intercultural Relations, vol. 12, no. 3, Mar., pp. 233-246, 1988. https://doi.org/10.1016/0147-1767(88)90017-x

[16] C. Kelley, and J. Meyers, The Cross-cultural Adaptability Inventory: Self-assessment. MN: NCS Pearson, 1995.

[17] M. R. Hammer, M. J. Bernnett, and R. L. Wiseman, "Measuring intercultural sensitivity: The intercultural development inventory," International Journal of Intercultural Relations, vol. 27, no. 2. Feb., pp. 421-443, 2003. https://doi.org/10.1016/s0147-1767(03)00032-4 
[18] G. Pudikova, A. Kurilova, and V. Movchun, "Emerging technologies for developing cross-cultural competency," International Journal of Emerging Technologies in Learning, vol. 14, no. 21, Nov., pp. 46-59, 2019. https://doi.org/10.3991/ijet.v14i21.11194

[19] C. Sinicrope, J. M. Norris, and Y. Watanabe, "Understanding and assessing intercultural competence: A summary of theory, research, and practice," Second Language Studies, vol. 26, no.1, Jan., pp. 1-58, 2007.

[20] B. Z. Peng, "Construction and application of the BEST teaching mode of college English in big data," International Journal of Emerging Technologies in Learning, vol. 12, no. 9, Sep., pp. 41-50, 2017. https://doi.org/10.3991/ijet.v12i09.7483

[21] Y. C. Gao, "The theoretical framework of the evaluation system of intercultural communication competence of Chinese university students," Foreign Language World, vol. 4, no. 8, Aug., pp. 80-88, 2014.

[22] W. P. Wu, W. Fan, and R. Z. Peng, "Analysis of Chinese university students' intercultural competence dimensions and assessment scales," Foreign Language Teaching and Research, vol. 4, no. 7, July, pp. 583-584, 2013.

\section{Author}

Bingzhuan Peng is a Professor in the Harbin University of Science and Technology, Harbin 150080, China (pengbingzhuan@163.com)

Article submitted 2021-01-20. Resubmitted 2021-03-03. Final acceptance 2021-03-04. Final version published as submitted by the authors. 